\title{
Perinatal and Familial Risk Factors Are Associated with Full Syndrome and Subthreshold Attention-Deficit Hyperactivity Disorder in a Korean Community Sample
}

\author{
Hyo-Won Kim ${ }^{1}$ \\ Soo-Churl Cho' \\ Boong-Nyun Kim ${ }^{1}$ \\ Jae-Won Kim ${ }^{1}$ \\ Min-Sup Shin ${ }^{1}$ \\ Yeni Kim² \\ ${ }^{1}$ Division of Child and \\ Adolescent Psychiatry, \\ Department of Neuropsychiatry, \\ Seoul National University \\ College of Medicine, Seoul, \\ 2Department of Neuropsychiatry, \\ Seoul National Hospital, Seoul, Korea
}

\section{Correspondence \\ Boong-Nyun Kim, MD, PhD \\ Division of Child and \\ Adolescent Psychiatry, \\ Department of Neuropsychiatry, \\ Seoul National University \\ College of Medicine, 101 Daehak-ro, \\ Jongno-gu, Seoul 110-769, Korea \\ Tel +82-2-2072-3647 \\ Fax $+82-2-744-5774$ \\ E-mail kbn1@snu.ac.kr}

(c) This is an Open Access article distributed under the terms of the Creative Commons Attribution Non-Commercial License (http://creativecommons.org/licenses/by-nc/3.0) which permits unrestricted non-commercial use, distribution, and reproduction in any medium, provided the original work is properly cited.

\begin{abstract}
Objective The objective of this study was to examine the effect of perinatal and familial risk factors on full syndrome and subthreshold attention-deficit/hyperactivity disorder (ADHD) among Korean children and adolescents.
\end{abstract}

Methods A sample of 2,673 students was randomly selected from 19 representative schools in Seoul, Korea. The parents of the students completed the Diagnostic Interview Schedule for Children-version IV (DISC-IV), as well as questionnaires on perinatal and familial risk factors.

Results Maternal stress and alcohol use during pregnancy, parental marital discord, parental separation or divorce, changes in primary caregivers, and notbreastfeeding were significantly associated with full syndrome ADHD; however, maternal stress during pregnancy was the only variable that differentiated subthreshold ADHD from non-ADHD.

Conclusion Our results provide evidence the perinatal and familial risk factors contribute to the development of ADHD in Korea children and adolescents, and suggest that these perinatal and familial risk factors are more closely related to full syndrome than to subthreshold ADHD.

Psychiatry Invest 2009;6:278-285

Key Words Attention-deficit/hyperactivity disorder, Family characteristics, Prevalence, Perinatal risk factors, Subthreshold.

Received: July 29, 2009 Revised: September 24, 2009 Accepted: October 9, 2009 Available online: November 5, 2009

\section{Introduction}

Attention-deficit/hyperactivity disorder (ADHD) is one of the most common psychiatric disorders occurring during childhood and adolescence and affects about $5 \%$ of school-aged children worldwide. ${ }^{1}$ Children with ADHD are known to suffer from cognitive and social deficits and to display behavior problems, resulting in disturbances in peer and family relationships, as well as poor academic achievement. ${ }^{2,3}$

ADHD is generally accepted as having a genetic basis but environmental influences have also been reported as contributing factors. The estimated heritability of ADHD ranges from 75 to $90 \%{ }^{4,5}$; the remaining variance in the ADHD phenotype $(10-25 \%)$ would be largely attributable to environmental factors. Possible environmental risk factors reported for ADHD have included perinatal complications, such as low birth weight, maternal smoking or alcohol consumption during pregnancy; and psychosocial adversities, such as parental marital discord, family dysfunction, low social class, and maternal psychopathology. ${ }^{6,7}$ These environmental risk factors may interact with genetic susceptibilities in complex ways, modifying the effect of the latter and influencing both the risk of developing and the subsequent course of the disorders. ${ }^{8,9}$ Nevertheless, few studies have evaluated the relationships between exposure to 
environmental risk factors and severity or clinical manifestations of psychiatric disorders.

Recently, there have been increased interests in children or adolescents who show inattentive or hyperactive/ impulsive symptoms of ADHD but do not meet the diagnostic threshold of ADHD, i.e., subthreshold ADHD. Subthreshold ADHD is reported to be more prevalent than full syndrome ADHD, ${ }^{10}$ associated with psychosocial adversity and functional impairment and related to a greater risk for developing clinical-level ADHD. ${ }^{11-13}$ Several researches which assessed the validity of subthreshold AD$\mathrm{HD}^{14-16}$ suggested that subthreshold ADHD might be a milder form of the disorder.

Although environmental risk factors have been implicated in the pathogenesis of full syndrome ADHD, ${ }^{6,7}$ to our knowledge, there was no previous study that evaluates the effect of the perinatal and familial risk factors on ADHD in a Korean epidemiological sample. Moreover, it remains unclear if these risk factors may also contribute to subthreshold ADHD. The aim of the present study was therefore to examine the effects of environmental risk factors on full syndrome and subthreshold ADHD in a Korean community sample.

\section{Methods}

This study, part of the 2005 Seoul Child and Adolescent Mental Health Survey, ${ }^{17}$ was conducted from September through December 2005. The research design in this study has been described in detail previously. ${ }^{16} \mathrm{Se}$ oul was divided into six districts based on socioeconomic status (SES), and 19 representative elementary, middle and high schools were randomly selected. Ten classes were randomly selected from each elementary school, and three classes were randomly selected from each middle and high school. Parents of 2,673 students completed the Diagnostic Interview Schedule for Children VersionIV (DISC-IV). ${ }^{18}$ The biological mother served as the informant in $94.3 \%$ of the cases. In-person interviews with parents, conducted by trained laypersons in the schools attended by the child subjects, involved administering the Korean version of the DISC-IV and questionnaire on perinatal and familial risk factors. All interviewers were college students majoring in psychology or education.

All 19 selected schools agreed to participate in the study. The Institutional Review Board of the Seoul National University Hospital and the Seoul School Health Promotion Center approved the study. Written informed consent was obtained from parents before each interview.

\section{Assessment measures}

Psychiatric disorders were assessed, according to the
Diagnostic and Statistical Manual of Mental Disorders4 th version (DSM-IV), ${ }^{19}$ with the Korean version of the DISC-IV. Interviews were organized according to six diagnostic sections: anxiety disorders, mood disorders, disruptive behavior disorders, substance use disorders, schizophrenia, and miscellaneous disorders (eating, elimination, and tic disorders, pica, and trichotillomania).

In this study, the DISC-IV scoring algorithms for diagnoses were based on data obtained from parents. Good test-retest reliability for the DISC-IV has been reported. ${ }^{18}$ The reliability and validity of the Korean version of the DISC-IV have been previously established. ${ }^{20}$

Parents also completed structured questionnaires on perinatal and familial risk factors for ADHD. Questions explored the following: 1) Prenatal risks; maternal stress and depression during pregnancy, maternal smoking/alcohol/caffeine consumption during pregnancy, 2) Obstetrical risks; antenatal hemorrhage, preterm labor, and mode of delivery (vaginal or cesarean), 3) Postnatal risks; birth weight, incubator use, physical abnormalities at birth, and breastfeeding or not-breastfeeding, 4) Familial risks; parental marital discord, stability of parental marriage, primary caregiver, changes in caregivers, and paternal loss of job.

\section{Definitions of full syndrome and subthreshold disorders}

Full syndrome and subthreshold disorders were identified on the basis of data from the DISC-IV interviews. Full syndrome ADHD was defined according to the DSMIV criteria for ADHD. Subthreshold ADHD was operationally defined as the presence of at least three but no more than five inattentive and/or hyperactive/impulsive symptoms. Children also had to fulfill DSM-IV ADHD age-of-onset and impairment criteria to qualify for a diagnosis of subthreshold ADHD. This definition of subthreshold ADHD was the identical to the one employed in prior studies conducted in Western countries. ${ }^{14,21}$ To define subtyping for subthreshold ADHD, we implemented the same threshold used in the DSM-IV $(6 / 9=0.67)$. Thus, those with both 3-5 inattentive and 3-5 hyperactive/impulsive symptoms were considered subthreshold ADHD combined type. Subjects with 3-5 symptoms in just one dimension were considered either subthreshold ADHD inattentive or hyperactive/impulsive type. The subjects who did not qualify for either full syndrome or subthreshold ADHD were used as the control group for each analysis.

\section{Data analysis}

The chi-squared test or Fisher's exact test (categorical variables) and univariate analysis of variance (ANOVA; dimensional data) were performed to assess differences 
in demographic data and risk factors among the three groups. Unadjusted and adjusted odds ratio (OR) were obtained by logistic regression analyses. Logistic regressions analyses were performed to assess predictors of full syndrome or subthreshold ADHD compared to non-ADHD in multivariate contexts. In these models, age, gender, SES and significant variables emerging in previous analyses were entered as potential predictors.

Statistical analysis was performed using Statistical Package for Social Science (SPSS, version 12.0; SPSS, Inc, Chicago, IL, USA), and statistical significance was defined for all other comparisons at $\mathrm{p}<0.05$; all comparisons were two-tailed.

\section{Results}

\section{Prevalence and demographic characteristics}

(Table 1, Figure 1)

The one-year prevalence rate for full syndrome ADHD in Korean children and adolescents was 4.60\% [95\% confidence interval $(\mathrm{CI})=3.85-5.48]$. In addition, $8.64 \%$ (95\% CI=7.62-9.79) of children and adolescents were diagnosed with subthreshold ADHD. Table 1 shows the demographic characteristics of the total sample of 354 ADHD children (123 children with full syndrome; 231 subthreshold ADHD) and 2,319 non-ADHD children.

The mean age of subjects with full syndrome ADHD, subthreshold ADHD and non-ADHD children were 10.0 [standard deviation $(\mathrm{SD})=2.9$ ], $10.9(\mathrm{SD}=3.0)$ and 11.2 $(\mathrm{SD}=3.1)$. The mean age of children with full syndrome ADHD were significantly lower compared to those of subthreshold ADHD and non-ADHD children $(\mathrm{p}<0.001)$. The sample was divided into four three-grade bands to allow comparisons of prevalence rates across developmental stages (Figure 1). The prevalence rates for full

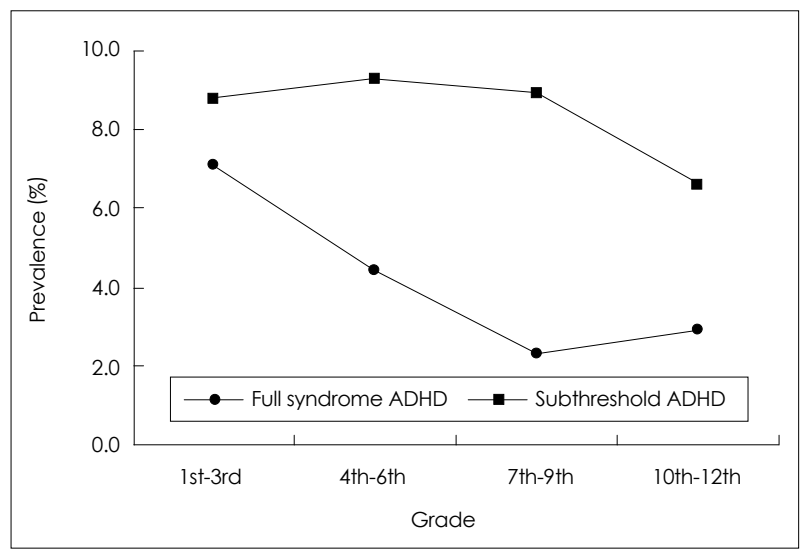

FIGURE 1. Prevalence of full syndrome and subthreshold ADHD according to the grade. ADHD: attention-deficit/hyperactivity disorder.

TABLE 1. Demographic characteristics

\begin{tabular}{|c|c|c|c|c|c|c|}
\hline & $\begin{array}{l}\text { Full syndrome ADHD } \\
\qquad N=123\end{array}$ & $\begin{array}{l}\text { Subthreshold ADHD } \\
\qquad N=231\end{array}$ & $\begin{array}{l}\text { No ADHD } \\
\mathrm{N}=2,319\end{array}$ & $\chi^{2}$ or $F$ & $d f$ & $\mathrm{p}^{\dagger}$ \\
\hline \multicolumn{7}{|l|}{ Age (years) } \\
\hline Mean (SD) & $10.0(2.9)$ & $10.9(3.0)$ & $11.2(3.1)$ & 9.71 & 2 & $<0.001^{\ddagger}$ \\
\hline Gender, n (\%) & & & & 59.98 & 2 & $<0.001$ \\
\hline Males & 99 (80.5) & $144(62.3)$ & $1,127(48.6)$ & & & \\
\hline SES, ${ }^{*}$ (\%) & & & & 10.46 & 4 & 0.033 \\
\hline High & $40(40.0)$ & 65 (35.9) & $832(44.9)$ & & & \\
\hline Middle & $53(53.0)$ & 109 (60.2) & $966(52.1)$ & & & \\
\hline Low & $7(7.0)$ & $7(3.9)$ & 55 ( 3.0$)$ & & & \\
\hline Subtype, n (\%) & & & & 23.6 & 2 & $<0.001$ \\
\hline Inattentive & $91(74.0)$ & $195(84.4)$ & & & & \\
\hline Hyperactive-impulsive & $12(9.8)$ & $0(0)$ & & & & \\
\hline Combined & $20(16.3)$ & $36(15.6)$ & & & & \\
\hline \multicolumn{7}{|l|}{ Comorbid disorders, n (\%) } \\
\hline ODD & $23(18.7)$ & 32 (13.9) & $58(2.5)$ & 133.56 & 2 & $<0.001$ \\
\hline Conduct disorder & $5(4.1)$ & $3(1.3)$ & $4(0.2)$ & & & $<0.001$ \\
\hline Depressive disorder & $4(3.3)$ & $2(0.9)$ & $2(0.1)$ & & & $<0.001$ \\
\hline Anxiety disorder & $31(25.2)$ & $29(12.6)$ & $165(7.1)$ & 55.19 & 2 & $<0.001$ \\
\hline Tic disorder & $6(4.9)$ & $9(3.9)$ & $38(1.6)$ & 11.07 & 2 & 0.007 \\
\hline Enuresis & $4(3.3)$ & $1(0.4)$ & $16(0.7)$ & & & 0.028 \\
\hline
\end{tabular}

*Numbers in the groups differ due to missing data, ${ }^{\dagger}$ ANOVA, $\chi^{2}$-test or Fisher's exact test among the three groups, except for ADHD subtype where comparison was made between full syndrome and subthreshold ADHD, ‡Represents that the mean age of children with full syndrome ADHD were significantly lower compared to those of subthreshold ADHD and non-ADHD children according to the Bonferroni post hoc analysis. ADHD: attention-deficit/hyperactivity disorder, ODD: oppositional defiant disorder, SES: socioeconomic status (by income), ANOVA: analysis of variance 
syndrome and subthreshold ADHD according to stages were significantly different $\left(\chi^{2}=25.86, \mathrm{df}=6, \mathrm{p}<0.001\right)$. The prevalence rates of full syndrome ADHD tended to decrease with age. However, the prevalence of subthreshold ADHD did not differ among the four groups $\left(\chi^{2}=\right.$ 2.50, $\mathrm{df}=3, \mathrm{p}=0.475$ ).

Boys were four times more likely than girls to experience full syndrome $\operatorname{ADHD}\left(\chi^{2}=47.50, \mathrm{df}=1, \mathrm{p}<0.001\right)$; and 1.2 times more likely to experience subthreshold ADHD $\left(\chi^{2}=14.97, \mathrm{df}=1, \mathrm{p}<0.001\right)$. Full syndrome and subthreshold ADHD presented different gender distributions $\left(\chi^{2}=12.28, \mathrm{df}=1, \mathrm{p}<0.001\right)$. SES did not significantly differ in full syndrome $\left(\chi^{2}=4.97, \mathrm{df}=2, \mathrm{p}=0.083\right)$ or subthreshold $\operatorname{ADHD}\left(\chi^{2}=5.15, \mathrm{df}=2, \mathrm{p}=0.076\right)$ compared to the control. However, subthreshold ADHD was more prevalent among those in upper socioeconomic groups $\left(\chi^{2}=\right.$ $10.46, \mathrm{df}=2, \mathrm{p}=0.033$ ) compared to full syndrome ADHD.

ADHD-predominantly inattentive type was most prevalent both in full syndrome and subthreshold ADHD groups, followed by combined type, and hyperactive-impulsive type. Subthreshold ADHD cases also presented the higher prevalence of ADHD-predominantly inattentive type, compared to the full syndrome one $(p<0.001)$.

Children with both full syndrome and subthreshold ADHD experienced significantly higher comorbid anxiety, mood, oppositional defiant, conduct, and tic disorders than the controls $(\mathrm{p}=0.004, \mathrm{p}=0.043, \mathrm{p}<0.001, \mathrm{p}=0.020, \mathrm{p}=$ $0.022 ; \mathrm{p}<0.001, \mathrm{p}<0.001, \mathrm{p}<0.001, \mathrm{p}<0.001, \mathrm{p}=0.021)$. Enuresis was significantly higher in subthreshold ADHD compared to the controls $(\mathrm{p}=0.016)$. The comorbid rate were not significantly different between full syndrome and subthreshold ADHD except for anxiety disorder which is higher in full syndrome ADHD ( $\mathrm{p}=0.003)$.

\section{Perinatal and familial risk factors for full syndrome and subthreshold attention- deficit/hyperactivity disorder}

Table 2 illustrated the prenatal risk factors in children with full syndrome and subthreshold ADHD. Among perinatal risk factors, maternal stress (adjusted $\mathrm{OR}=2.82$, 95\% $\mathrm{CI}=1.84-4.33$ ), maternal depression (adjusted $\mathrm{OR}=$ $3.23,95 \% \mathrm{CI}=1.27-8.21)$ and alcohol intake during pregnancy (adjusted $\mathrm{OR}=3.31,95 \% \mathrm{CI}=1.59-6.91$ ) were significantly associated with full syndrome ADHD; maternal stress during pregnancy with subthreshold ADHD (adjusted $\mathrm{OR}=1.88,95 \% \mathrm{CI}=1.36-2.60$ ). The frequencies of prenatal risk factors were not significantly different between full syndrome and subthreshold ADHD.

In Table 3, we presented the unadjusted and adjusted OR of obstetrical and postnatal risk factors. None of the obstetrical risk factors was significantly related to full syndrome or subthreshold ADHD. Regarding postnatal risk factors, only not-breastfeeding was significantly related to full syndrome ADHD (adjusted OR=1.82, 95\% $\mathrm{CI}=1.21-2.75$ ). The frequency of not-breastfeeding was also significantly higher in full syndrome ADHD compared to the subthreshold ADHD ( $p=0.035)$.

Among familial risk factors, parental marital discord (adjusted $\mathrm{OR}=2.44,95 \% \mathrm{CI}=1.05-5.67$ ), parental separation or divorce (adjusted $\mathrm{OR}=5.10,95 \% \mathrm{CI}=2.59-10.07$ ), primary caregiver who is not a biological parent (adjusted $\mathrm{OR}=4.27,95 \% \mathrm{CI}=2.61-6.97)$ and changes in caregiver (adjusted $\mathrm{OR}=2.30,95 \% \mathrm{CI}=1.37-3.83$ ) showed significant association with full syndrome ADHD; paternal loss

TABLE 2. Prenatal risk factors in children with full syndrome and subthreshold ADHD: $n$ (\%), odds ratio (OR)(95\% confidence interval)

\begin{tabular}{|c|c|c|c|c|c|}
\hline & $\begin{array}{l}\text { Full syndrome ADHD } \\
\qquad N=100\end{array}$ & $\begin{array}{c}\text { Subthreshold ADHD } \\
\qquad N=182\end{array}$ & $\chi^{2}$ or $\mathrm{F}$ & df & $\mathrm{p}^{*}$ \\
\hline Maternal stress during pregnancy & $48(48.0 \%)$ & $71(39.0 \%)$ & 2.14 & 1 & 0.144 \\
\hline Unadjusted OR & $2.91(1.92-4.41)$ & $1.96(1.42-2.70)$ & & & \\
\hline Adjusted OR & $2.82(1.84-4.33)$ & $1.88(1.36-2.60)$ & & & \\
\hline Maternal depression during pregnancy & $6(6.0 \%)$ & $5(2.7 \%)$ & 1.82 & 1 & 0.177 \\
\hline Unadjusted OR & $3.61(1.48-8.84)$ & $1.60(0.62-4.15)$ & & & \\
\hline Adjusted OR & $3.23(1.27-8.21)$ & $1.53(0.58-3.99)$ & & & \\
\hline Alcohol intake during pregnancy & $10(10.0 \%)$ & $11(6.0 \%)$ & 1.47 & 1 & 0.226 \\
\hline Unadjusted OR & $3.30(1.64-6.64)$ & $1.91(0.99-3.69)$ & & & \\
\hline Adjusted OR & $3.31(1.59-6.91)$ & $1.80(0.93-3.50)$ & & & \\
\hline Maternal smoking during pregnancy & $(-)$ & $2(1.1 \%)$ & & & 0.541 \\
\hline Unadjusted OR & & $4.21(0.81-21.87)$ & & & \\
\hline Adjusted OR & & $4.01(0.75-21.51)$ & & & \\
\hline Caffeine intake during pregnancy & $29(29.0 \%)$ & $44(24.2 \%)$ & 0.78 & 1 & 0.376 \\
\hline Unadjusted OR & $1.30(0.83-2.02)$ & $1.01(0.71-1.45)$ & & & \\
\hline Adjusted OR & $1.28(0.81-2.02)$ & 1.04 (0.73-1.49) & & & \\
\hline
\end{tabular}

The reference group for determining the OR was "no ADHD". Adjusted estimates take account of age, gender and socioeconomic status. ${ }^{2} \chi 2$-test or Fisher's exact test between the full syndrome and subthreshold ADHD. ADHD: attention-deficit/hyperactivity disorder 
of job (adjusted $\mathrm{OR}=1.73,95 \% \mathrm{CI}=1.23-2.45$ ), parental marital discord (adjusted OR=2.74, 95\% $\mathrm{CI}=1.48-5.05$ ), and primary caregiver who is not a biological parent (ad- justed $\mathrm{OR}=1.81,95 \% \mathrm{CI}=1.19-2.73)$ with subthreshold ADHD (Table 4). The frequency of parental separation or divorce and change in caregiver were significantly hi-

TABLE 3. Obstetrical and postnatal risk factors in children with full syndrome and subthreshold ADHD: $n$ (\%), odds ratio (OR)(95\% confidence interval)

\begin{tabular}{|c|c|c|c|c|c|}
\hline & $\begin{array}{l}\text { Full syndrome ADHD } \\
\qquad N=100\end{array}$ & $\begin{array}{l}\text { Subthreshold ADHD } \\
\qquad N=182\end{array}$ & $\chi^{2}$ or $F$ & df & $\mathrm{p}^{*}$ \\
\hline \multicolumn{6}{|l|}{ Obstetrical risk factors } \\
\hline Antenatal hemorrhage & $6(6.0 \%)$ & $11(6.0 \%)$ & 0.00 & 1 & 0.988 \\
\hline Unadjusted OR & $1.11(0.48-2.60)$ & $1.12(0.59-2.13)$ & & & \\
\hline Adjusted OR & $1.24(0.52-2.99)$ & $1.21(0.63-2.31)$ & & & \\
\hline Preterm labor & $3(3.0 \%)$ & $5(2.7 \%)$ & & & 1.000 \\
\hline Unadjusted OR & $1.16(0.36-3.77)$ & $1.27(0.51-3.20)$ & & & \\
\hline Adjusted OR & $0.84(0.25-2.81)$ & $1.12(0.44-2.84)$ & & & \\
\hline Mode of delivery, casearean & $30(30.0 \%)$ & $56(30.8 \%)$ & 0.02 & 1 & 0.893 \\
\hline Unadjusted OR & $1.15(0.74-1.79)$ & $1.07(0.77-1.44)$ & & & \\
\hline Adjusted OR & $1.33(0.85-2.74)$ & $1.10(0.79-1.55)$ & & & \\
\hline \multicolumn{6}{|l|}{ Postnatal risk factors } \\
\hline Low birth weight & $3(3.0 \%)$ & $6(3.3 \%)$ & & & 1.000 \\
\hline Unadjusted OR & $1.14(0.35-3.71)$ & $1.04(0.44-2.43)$ & & & \\
\hline Adjusted OR & $1.01(0.31-3.37)$ & $1.03(0.36-2.94)$ & & & \\
\hline Physical abnormalities at birth & $14(14.0 \%)$ & $25(13.7 \%)$ & 0.00 & 1 & 0.951 \\
\hline Unadjusted OR & $1.68(0.93-3.03)$ & $1.61(1.03-2.53)$ & & & \\
\hline Adjusted OR & $1.49(0.81-2.74)$ & $1.57(0.99-2.47)$ & & & \\
\hline Incubator use & $8(8.0 \%)$ & $11(6.0 \%)$ & 0.39 & 1 & 0.531 \\
\hline Unadjusted OR & $1.67(0.78-3.56)$ & $1.15(0.60-2.19)$ & & & \\
\hline Adjusted OR & 1.75 (0.80-3.82) & $1.12(0.58-2.13)$ & & & \\
\hline Not-breastfeeding & $52(52.0 \%)$ & 71 (39.0\%) & 4.43 & 1 & 0.035 \\
\hline Unadjusted OR & $1.79(1.20-2.68)$ & $1.06(0.77-1.44)$ & & & \\
\hline Adjusted OR & $1.82(1.21-2.75)$ & 1.05 (0.77-1.44) & & & \\
\hline
\end{tabular}

The reference group for determining the OR was "no ADHD". Adjusted estimates take account of age, gender and socioeconomic status. * $\chi^{2}$-test or Fisher's exact test between the full syndrome and subthreshold ADHD. ADHD: attention-deficit/hyperactivity disorder

TABLE 4. Familial risk factors in children with full syndrome and subthreshold ADHD: $n(\%)$, odds ratio (OR)(95\% confidence interval)

\begin{tabular}{|c|c|c|c|c|c|}
\hline & $\begin{array}{l}\text { Full syndrome ADHD } \\
\qquad \mathrm{N}=100\end{array}$ & $\begin{array}{l}\text { Subthreshold ADHD } \\
\qquad \mathrm{N}=182\end{array}$ & $\chi^{2}$ or $\mathrm{F}$ & df & $p^{*}$ \\
\hline Paternal loss of job & $28(28.0 \%)$ & $59(32.4 \%)$ & 0.59 & 1 & 0.442 \\
\hline Unadjusted OR & $1.49(0.95-2.34)$ & $1.81(1.30-2.52)$ & & & \\
\hline Adjusted OR & $1.48(0.91-2.41)$ & $1.73(1.23-2.45)$ & & & \\
\hline Parental marital discord & $7(7.0 \%)$ & $14(7.7 \%)$ & 0.05 & 1 & 0.832 \\
\hline Unadjusted OR & $2.50(1.11-5.63)$ & $2.72(1.49-4.99)$ & & & \\
\hline Adjusted OR & $2.44(1.05-5.67)$ & $2.74(1.48-5.05)$ & & & \\
\hline Parental separation or divorce & $15(15.0 \%)$ & 9 (4.9\%) & 8.38 & 1 & 0.004 \\
\hline Unadjusted OR & $4.89(2.68-8.92)$ & $1.42(0.69-2.89)$ & & & \\
\hline Adjusted OR & $5.10(2.59-10.07)$ & $1.23(0.58-2.58)$ & & & \\
\hline Primary caregiver was not a biological parent & $22(22.0 \%)$ & $32(17.6 \%)$ & 0.81 & 1 & 0.367 \\
\hline Unadjusted OR & $2.25(1.37-3.69)$ & $1.73(1.15-2.60)$ & & & \\
\hline Adjusted OR & $4.27(2.61-6.97)$ & $1.81(1.19-2.73)$ & & & \\
\hline Changes in caregiver & $28(28.0 \%)$ & 20 (11.0\%) & 13.22 & 1 & $<0.001$ \\
\hline Unadjusted OR & $4.05(2.54-6.44)$ & $1.29(0.79-2.11)$ & & & \\
\hline Adjusted OR & 2.30 (1.37-3.83) & $1.33(0.81-2.18)$ & & & \\
\hline
\end{tabular}

The reference group for determining the OR was "no ADHD". Adjusted estimates take account of age, gender and socioeconomic status. * $\chi 2$-test or Fisher's exact test between the full syndrome and subthreshold ADHD. ADHD: attention-deficit/hyperactivity disorder 
gher in full syndrome ADHD compared to subthreshold $\operatorname{ADHD}(\mathrm{p}=0.004, \mathrm{p}<0.001$, respectively).

We ran two separate multivariate logistic regression analyses to test which risk factors differentiated full syndrome or subthreshold ADHD from non-ADHD in a multivariate context. In these analyses, we retained age, gen$\mathrm{der}$, and those risk factors that were significant $(\mathrm{p}<0.05)$ in the analyses above. Full syndrome ADHD was predicted independently by age ( $\mathrm{OR}=1.17,95 \% \mathrm{CI}=1.07-1.28)$, gender $(\mathrm{OR}=6.21,95 \% \mathrm{CI}=3.33-11.58)$, maternal stress during pregnancy $(\mathrm{OR}=2.37,95 \% \mathrm{CI}=1.43-3.91)$, alcohol consumption during pregnancy $(\mathrm{OR}=2.83,95 \% \mathrm{CI}=1.20$ 6.70), not-breastfeeding ( $\mathrm{OR}=1.69,95 \% \mathrm{CI}=1.04-2.75)$, parental marital discord $(\mathrm{OR}=2.69,95 \% \mathrm{CI}=1.05-6.90)$, parental separation or divorce $(\mathrm{OR}=4.38,95 \% \mathrm{CI}=1.82$ $10.54)$, and changes in primary caregivers $(\mathrm{OR}=2.90,95 \%$ $\mathrm{CI}=1.49-5.63)$. In the second model, gender $(\mathrm{OR}=1.60$, $95 \% \mathrm{CI}=1.14-2.25)$ and maternal stress during pregnancy $(\mathrm{OR}=1.51,95 \% \mathrm{CI}=1.05-2.16)$ emerged as strong predictors of subthreshold ADHD versus non-ADHD status.

\section{Discussion}

To the best of our knowledge, this is the first study to investigate the effect of perinatal and familial risk factors on full syndrome and subthreshold ADHD in a large Asian community sample. In addition, this study provided the prevalence estimates of full syndrome and subthreshold ADHD in Korean children and adolescents covering wide range of age.

In this study, the prevalence rates for full syndrome and subthreshold ADHD in Korean children and adolescents were estimated at $4.60 \%$ and $8.64 \%$, respectively. We also found that perinatal complications and familial risk factors played different roles in relation to the diagnostic status of ADHD. This study suggests that maternal stress or alcohol consumption during pregnancy, parental marital discord, parental separation or divorce, changes in primary caregivers and not-breastfeeding contribute to the clinical manifestations and/or severity of symptoms of ADHD.

The $4.60 \%$ prevalence rate of ADHD found in this study is similar to that reported for other cultures. ${ }^{1,22}$ The male-to-female ratio of $4: 1$ in this study is also congruent with previous studies. ${ }^{23,24}$ The prevalence rates for full syndrome ADHD decreased with age, but those for subthreshold ADHD remained relatively constant across age groups. These results suggest that substantial portions of Korean adolescents are experiencing subthreshold ADHD. Subthreshold ADHD was also more prevalent in girls and those within the upper socioeconomic class. This result corresponds with the previous findings which showed that subthreshold ADHD defined by ADHD rating scale were more prevalent than full syndrome one, especially in girls. ${ }^{10,25}$ Subthreshold ADHD has been reported to be valid as a meaningful clinical entity ${ }^{11-15}$ and clinically relevant regarding temperament and comorbidity in our previous study. ${ }^{16}$ It is also reportedly related to psychosocial impairments, high risk for subsequently developing $\mathrm{ADHD},{ }^{11,13}$ and a predisposition to develop other comorbid subthreshold and full syndrome disorders. ${ }^{10}$ Thus increased awareness of subthreshold ADHD is needed, particularly in adolescents, girls, and those in high SES groups.

We hypothesized that maternal stress during pregnancy would predict the development of both full syndrome and subthreshold ADHD. Maternal stress during pregnancy has been reported to increase plasma levels of cortisol and corticotrophin-releasing hormone in the mother and the fetus; to alter functioning of the hypothalamus-pituitary-adrenal (HPA) axis in the fetus; and to correlate with structural changes in the hippocampus, frontal cortex, amygdala, and nucleus accumbens. ${ }^{26}$ Since the frontal cortex is one of the best-replicated brain regions in neuropathological and neuroimaging studies, ${ }^{24,27,28}$ maternal stress during pregnancy could modulate the pathogenesis of ADHD.

Alcohol consumption during pregnancy, not-breastfeeding, parental marital discord, parental separation or divorce, and changes in primary caregivers differentiated between full syndrome ADHD, but not subthreshold AD$\mathrm{HD}$, and the control group. These results indicate that the perinatal and familial risk factors were related to the more severe form of ADHD and contributed to the development of ADHD symptoms fulfilling the diagnostic criteria. Several studies of ADHD have suggested that genetic and environmental risk factors may act together, giving rise to the theory that some genes may influence the development and course of ADHD by affecting individual sensitivity to environmental adversity, and that the long-term clinical course of ADHD is influenced by prenatal, biological, and psychosocial environmental risk factors. ${ }^{9,29-31}$ The results of the present study are consistent with this theory, suggesting that at least some environmental adversities might modulate the clinical manifestations of ADHD.

In this study, fetal exposure to alcohol was related to ADHD, consistent with previous studies. Prenatal exposure to alcohol has been associated with hyperactivity, disruptive behaviors, delinquency problems, and increased risk for a range of psychiatric disorders and other psychosocial deficits. ${ }^{32,33}$ Although fetal exposure to maternal smoking is also associated with the development of $\mathrm{ADHD},{ }^{7,34,35}$ this study found no differences among full 
syndrome ADHD, subthreshold ADHD, and non-ADHD children. This finding might be an artifact of the size of the sub-sample exposed to tobacco in utero; that is, this group may have been too small to allow for statistically significant results. Smoking rates among women are considerably lower in Korea than in other countries. ${ }^{36}$ Thus maternal tobacco smoking during pregnancy would also occur at a low rate. The sub-group of the subjects with low birth weights was also too small to show statistical differences, although low birth weight has been consistently associated with ADHD. ${ }^{7,37,38}$ More extensive studies utilizing larger samples are required to examine the relationships among fetal exposure to smoking, low birth weight, and ADHD in the Korean population.

We found that not-breastfeeding (i.e., using formula milk to feed) was associated with ADHD. Breastfeeding has been related to the cognitive development of infants, either because some constituents of breast milk [e.g., docosahexaenoic acid (DHA) and arachidonic acid] play roles in brain development during fetal and infant development, ${ }^{39,40}$ or because physical and social interactions are enhanced during breastfeeding. One case-control study suggested that a shorter duration of breastfeeding served as an environmental risk factor for ADHD symptoms. ${ }^{41}$ The present study is the first epidemiological study to show a possibly protective role for breastfeeding in regard to the development of ADHD.

Subjects with ADHD were more likely to report familial risk factors, including parental marital discord, parental separation or divorce, and changes in primary caregivers in this study. Rutter has identified six characteristics of family environments that serve as risk factors for ADHD (i.e., severe marital discord, low social class, large family size, paternal criminality, maternal mental disorder, and foster placement). ${ }^{42,43}$ Indeed, numerous investigations have emphasized the risks related to the development and course of ADHD posed by an adverse family environment. ${ }^{6}$ Moreover, in a recent study, psychosocial adversity was described as modulating the impact of the dopamine transporter (DAT1) gene on the development of ADHD symptoms ${ }^{44}$ However, since familial risk factors including paternal loss of job, parental marital discord, parental separation or divorce could be related to the parental psychopathology, these results should be viewed with caution. More comprehensive studies are needed to explore how environmental factors work in the development of ADHD.

Several limitations should be considered in interpreting the results of this study. First, our indicators of perinatal complications were collected retrospectively and therefore were susceptible to recall bias. However, retrospective self-reports of smoking or birth weight have been shown to be relatively accurate, corresponding with contemporaneous reports or medical records. ${ }^{45,46}$ Second, the cross-sectional nature of this study limits our ability to assess direct causal associations between familial risk factors and ADHD. Thus prospective longitudinal studies are needed to confirm our results. This investigation was also limited by its omission of information on potential confounding variables, such as maternal IQ, parental psychopathology, and family psychiatric histories.

Despite these caveats, this study offers the following strengths: 1) a community sample was used, thereby minimizing selection bias; 2) standardized instruments were used to diagnose ADHD; and 3) subjects were drawn from a non-Western, Asian culture.

Our results provide evidence the perinatal and familial risk factors reported in western culture similarly contribute to the development of ADHD in Korea children and adolescents, and suggest that these perinatal and familial environmental risk factors are more closely related to full syndrome than to subthreshold ADHD.

\section{- Acknowledgments}

This study was supported by the Seoul Child and Adolescent Mental Health Center Grant (07-2005-013-02).

\section{REFERENCES}

1. Polanczyk G, de Lima MS, Horta BL, Biederman J, Rohde LA. The worldwide prevalence of ADHD: a systematic review and metaregression analysis. Am J Psychiatry 2007;164:942-948.

2. Biederman J. Attention-deficit/hyperactivity disorder: a life-span perspective. J Clin Psychiatry 1998;59 Suppl 7:4-16.

3. Stevenson J, Asherson P, Hay D, Levy F, Swanson J, Thapar A, et al. Characterizing the ADHD phenotype for genetic studies. Dev Sci 2005;8:115-121.

4. Martin N, Scourfield J, McGuffin P. Observer effects and heritability of childhood attention-deficit hyperactivity disorder symptoms. Br J Psychiatry 2002;180:260-265.

5. Eaves LJ, Silberg JL, Meyer JM, Maes HH, Simonoff E, Pickles A, et al. Genetics and developmental psychopathology: 2. The main effects of genes and environment on behavioral problems in the Virginia Twin Study of Adolescent Behavioral Development. J Child Psychol Psychiatry 1997;38:965-980.

6. Biederman J, Milberger S, Faraone SV, Kiely K, Guite J, Mick E, et al. Family-environment risk factors for attention-deficit hyperactivity disorder. A test of Rutter's indicators of adversity. Arch Gen Psychiatry 1995;52:464-470.

7. Banerjee TD, Middleton F, Faraone SV. Environmental risk factors for attention-deficit hyperactivity disorder. Acta Paediatr 2007;96:12691274.

8. Rutter M, Moffitt TE, Caspi A. Gene-environment interplay and psychopathology: multiple varieties but real effects. J Child Psychol Psychiatry 2006;47:226-261.

9. Thapar A, Langley K, Asherson P, Gill M. Gene-environment interplay in attention-deficit hyperactivity disorder and the importance of a developmental perspective. Br J Psychiatry 2007;190:1-3.

10. Lewinsohn PM, Shankman SA, Gau JM, Klein DN. The prevalence and co-morbidity of subthreshold psychiatric conditions. Psychol Med 2004;34:613-622. 
11. Scahill L, Schwab-Stone M, Merikangas KR, Leckman JF, Zhang H, Kasl S. Psychosocial and clinical correlates of ADHD in a community sample of school-age children. J Am Acad Child Adolesc Psychiatry 1999;38:976-984.

12. Bird HR, Yager TJ, Staghezza B, Gould MS, Canino G, Rubio-Stipec M. Impairment in the epidemiological measurement of childhood psychopathology in the community. J Am Acad Child Adolesc Psychiatry 1990;29:796-803.

13. Sanford MN, Offord DR, Boyle MH, Peace A, Racine YA. Ontario child health study: social and school impairments in children aged 6 to 16 years. J Am Acad Child Adolesc Psychiatry 1992;31:60-67.

14. Faraone SV, Biederman J, Doyle A, Murray K, Petty C, Adamson JJ, et al. Neuropsychological studies of late onset and subthreshold diagnoses of adult attention-deficit/hyperactivity disorder. Biol Psychiatry 2006;60:1081-1087.

15. Faraone SV, Kunwar A, Adamson J, Biederman J. Personality traits among ADHD adults: implications of late-onset and subthreshold diagnoses. Psychol Med 2009;39:685-693.

16. Cho SC, Kim BN, Kim JW, Rohde LA, Hwang JW, Chungh DS, et al. Full syndrome and subthreshold attention-deficit/hyperactivity disorder in a Korean community sample: comorbidity and temperament findings. Eur Child Adolesc Psychiatry 2009;18:447-457.

17. Cho SC, Go BJ, Kim BN, Kim JW, Shin MS, Yoo HI, et al. The 2005 Seoul Child and Adolescent Mental Health Survey. Seoul: Seoul Child and Adolescent Mental Health Center; 2006.

18. Shaffer D, Fisher P, Lucas CP, Dulcan MK, Schwab-Stone ME. NIMH Diagnostic Interview Schedule for Children Version IV (NIMH DISCIV): description, differences from previous versions, and reliability of some common diagnoses. J Am Acad Child Adolesc Psychiatry 2000; 39:28-38.

19. American Psychiatric Association. Diagnostic and Statistical Manual of77 Mental Disorders. 4th ed. Washington DC: American Psychiatric Press; 1994

20. Cho SC, Kim BN, Kim JW, Kim HW, Choi HJ, Jung SW, et al. The reliability and validity of Diagnostic Interview Schedule for Children Version IV-Korean Version (DISC-IV). J Kor Acad Child Adolesc Psychiatry 2006;18:138-144.

21. Schmitz M, Denardin D, Laufer Silva T, Pianca T, Hutz MH, Faraone $\mathrm{S}$, et al. Smoking during pregnancy and attention-deficit/hyperactivity disorder, predominantly inattentive type: a case-control study. J Am Acad Child Adolesc Psychiatry 2006;45:1338-1345.

22. Faraone SV, Sergeant J, Gillberg C, Biederman J. The worldwide prevalence of ADHD: is it an American condition? World Psychiatry 2003;2:104-113.

23. Cantwell DP. Attention deficit disorder: a review of the past 10 years. J Am Acad Child Adolesc Psychiatry 1996;35:978-987.

24. Spetie L, Arnold EL. Attention-deficit hyperactivity disorder. In: Martin A, Volkmar FR, editors. Lewis's child and adolescent psychiatry. 4 ed. Philadelpia: Lipponcott Williams \& Wilkins; 2007. p.430-453.

25. Kim BN. Community based study for characteristics of children with mild sub-threshold attention deficit/hyperactivity disorder. J Korean Neuropsychiatr Assoc 2002;41:110-122.

26. Weinstock M. The long-term behavioural consequences of prenatal stress. Neurosci Biobehav Rev 2008;32:1073-1086.

27. Seidman LJ, Valera EM, Makris N. Structural brain imaging of attention-deficit/hyperactivity disorder. Biol Psychiatry 2005;57:1263-1272.

28. Bush G, Valera EM, Seidman LJ. Functional neuroimaging of attention-deficit/hyperactivity disorder: a review and suggested future directions. Biol Psychiatry 2005;57:1273-1284

29. Waldman ID. Gene-environment interactions reexamined: does mother's marital stability interact with the dopamine receptor D2 gene in the etiology of childhood attention-deficit/hyperactivity disorder? Dev Psychopathol 2007;19:1117-1128.

30. Brookes KJ, Mill J, Guindalini C, Curran S, Xu X, Knight J, et al. A common haplotype of the dopamine transporter gene associated with attention-deficit/hyperactivity disorder and interacting with maternal use of alcohol during pregnancy. Arch Gen Psychiatry 2006;63:74-81.

31. Thapar A, Langley K, Fowler T, Rice F, Turic D, Whittinger N, et al. Catechol O-methyltransferase gene variant and birth weight predict early-onset antisocial behavior in children with attention-deficit/hyperactivity disorder. Arch Gen Psychiatry 2005;62:1275-1278.

32. Huizink AC, Mulder EJ. Maternal smoking, drinking or cannabis use during pregnancy and neurobehavioral and cognitive functioning in human offspring. Neurosci Biobehav Rev 2006;30:24-41.

33. Mick E, Biederman J, Faraone SV, Sayer J, Kleinman S. Case-control study of attention-deficit hyperactivity disorder and maternal smoking, alcohol use, and drug use during pregnancy. J Am Acad Child Adolesc Psychiatry 2002;41:378-385.

34. Button TM, Maughan B, McGuffin P. The relationship of maternal smoking to psychological problems in the offspring. Early Hum Dev 2007;83:727-732.

35. Obel C, Linnet KM, Henriksen TB, Rodriguez A, Järvelin MR, Kotimaa A, et al. Smoking during pregnancy and hyperactivity-inattention in the offspring--comparing results from three Nordic cohorts. Int $\mathrm{J}$ Epidemiol 2008;38:698-705.

36. OECD. Percentage of females and males smoking daily 2005. 2007 [cited; Available from: http://masetto.sourceoecd.org/vl=1049619/cl= 34/ini=rcse/nw=1/rpsv/health2007/g3-1-02.htm]

37. Hultman CM, Torrång A, Tuvblad C, Cnattingius S, Larsson JO, Lichtenstein P. Birth weight and attention-deficit/hyperactivity symptoms in childhood and early adolescence: a prospective Swedish twin study. J Am Acad Child Adolesc Psychiatry 2007;46:370-377.

38. Lehn H, Derks EM, Hudziak JJ, Heutink P, van Beijsterveldt TC, Boomsma DI. Attention problems and attention-deficit/hyperactivity disorder in discordant and concordant monozygotic twins: evidence of environmental mediators. J Am Acad Child Adolesc Psychiatry 2007 46:83-91.

39. Cunnane SC, Francescutti V, Brenna JT, Crawford MA. Breast-fed infants achieve a higher rate of brain and whole body docosahexaenoate accumulation than formula-fed infants not consuming dietary docosahexaenoate. Lipids 2000;35:105-111.

40. Innis SM. Perinatal biochemistry and physiology of long-chain polyunsaturated fatty acids. J Pediatr 2003;143(4 suppl):S1-S8

41. Kadziela-Olech H, Piotrowska-Jastrzebska J. The duration of breastfeeding and attention deficit hyperactivity disorder. Rocz Akad Med Bialymst 2005;50:302-306.

42. Rutter M, Cox A, Tupling C, Berger M, Yule W. Attainment and adjustment in two geographical areas. I--The prevalence of psychiatric disorder. Br J Psychiatry 1975;126:493-509.

43. Rutter M, Quinton D. Psychiatric disorder: ecological factors and concepts of causation. In: McGurk H, editor. Ecological Factors in Human Development. Amsterdam: North Holland; 1977.

44. Laucht M, Skowronek MH, Becker K, Schmidt MH, Esser G, Schulze TG, et al. Interacting effects of the dopamine transporter gene and psychosocial adversity on attention-deficit/hyperactivity disorder symptoms among 15-year-olds from a high-risk community sample. Arch Gen Psychiatry 2007;64:585-590.

45. Fergusson DM, Horwood LJ, Lynskey MT. Maternal smoking before and after pregnancy: effects on behavioral outcomes in middle childhood. Pediatrics 1993;92:815-822.

46. Taylor E, Sandberg S, Thorley G, Giles S. The epidemiology of childhood hyperactivity. New York: Oxford University Press; 1991. 